\title{
Carbothermic Reduction of Vanadium Titanomagnetite by Microwave Irradiation and Smelting Behavior
}

\author{
Xuewei LV, ${ }^{*}$ Zhigang LUN, Jiaqing YIN and Chenguang BAI \\ School of Materials Science and Engineering, Chongqing University, 400044 China. \\ (Received on October 7, 2012; accepted on March 26, 2013)
}

\begin{abstract}
The recovery rate of the titanium is much low in the current process of the vanadium titanomagnetite resource in Panzhihua, China. The carbothermic reduction process in the microwave filed was proposed because the problem caused by $\mathrm{Ti}(\mathrm{C}, \mathrm{N})$ should be avoid and the $\mathrm{TiO}_{2}$ content in the slag should increase. The reduction behavior of the ore in microwave and the distribution of the elements during the smelting process were studied. The heating rate of the vanadium titanomagnetite in the microwave field can be divided into three stages: the very fast heating period in initial 25 minutes in which no apparent reduction happens, the slow heating period in which the solid reduction of the magnetite decreases the heating rate, another fast heating period in which the reduction of ilmenite happens. About $60 \%$ of iron from $1 \mathrm{~kg}$ of the ore and carbonaceous materials was obtained by an energy supply of $10 \mathrm{~kW}$ by microwave irradiation in $120 \mathrm{~min}$. The recovery ratios of $\mathrm{Fe}, \mathrm{V}$ and $\mathrm{Si}$ increase with increasing the reduction temperature. The addition of the $\mathrm{CaO}$ can increase the recovery ratio of $\mathrm{Fe}$ and $\mathrm{V}$, but decrease the recovery ratio of $\mathrm{Si}$.
\end{abstract}

KEY WORDS: titanomagnetite; microwave; reduction.

\section{Introduction}

There is a special and huge iron ore deposit called vanadium titanomagnetite, about 10 billion tonnage, in Panzhihua area, southwest of China. The average content of Fe and $\mathrm{TiO}_{2}$ is about $30 \%$ and $9 \%$ individually in the original mineral. ${ }^{1)}$ The whole flow sheet of the process is schematically shown in Fig. 1. The magnetite concentrate and the ilmenite concentrate are the two main products after the twice beneficiation process respectively, whose classical chemical composition are shown in Table 1. In the BF process, the elements such as Fe and V in magnetite concentrate are both reduced into hot metal, while most of the titanium in the concentrate was not reduced and remained in the slag. In the BOF process, the $\mathrm{V}$ in the hot metal is oxidized into the slag which is calcined with sodium salt or calcium salt and then leached to produce $\mathrm{V}_{2} \mathrm{O}_{5}$. For the EAF process, the Fe in the ilmenite concentrate is reduced to metal and the $\mathrm{Ti}$ is remained in the slag, forming the high $\mathrm{TiO}_{2}$ slag, which is used to produce titanium pigment by sulfate process or chlorination process. The recovery rate of the $\mathrm{Fe}, \mathrm{V}$, and $\mathrm{Ti}$ is about $70 \%, 39 \%$ and $13 \%$ individually. ${ }^{2)}$

Titanium is a very important and useful metal which is widely used in the aerospace and chemical industrial. Many countries regard the deposit of titanium as a strategic resource. China is abundant in titanium, account for about $48 \%$ of the world. However, the recovery rate of the titanium is too low in the current process of the vanadium titano-

* Corresponding author: E-mail: lvxuewei@163.com DOI: http://dx.doi.org/10.2355/isijinternational.53.1115 magnetite resource. As shown in Fig. 1, about 54\% titanium contained in the magnetite concentrate converts into blast furnace slag with little usage. Figure 2 shows the dependency of $\mathrm{TiO}_{2}$ content on the usage ratio of vanadium titanomagnetite and the change of viscosity with the content of $\mathrm{TiO}_{2}{ }^{3)}$ It indicates that the critical content of $\mathrm{TiO}_{2}$ is about

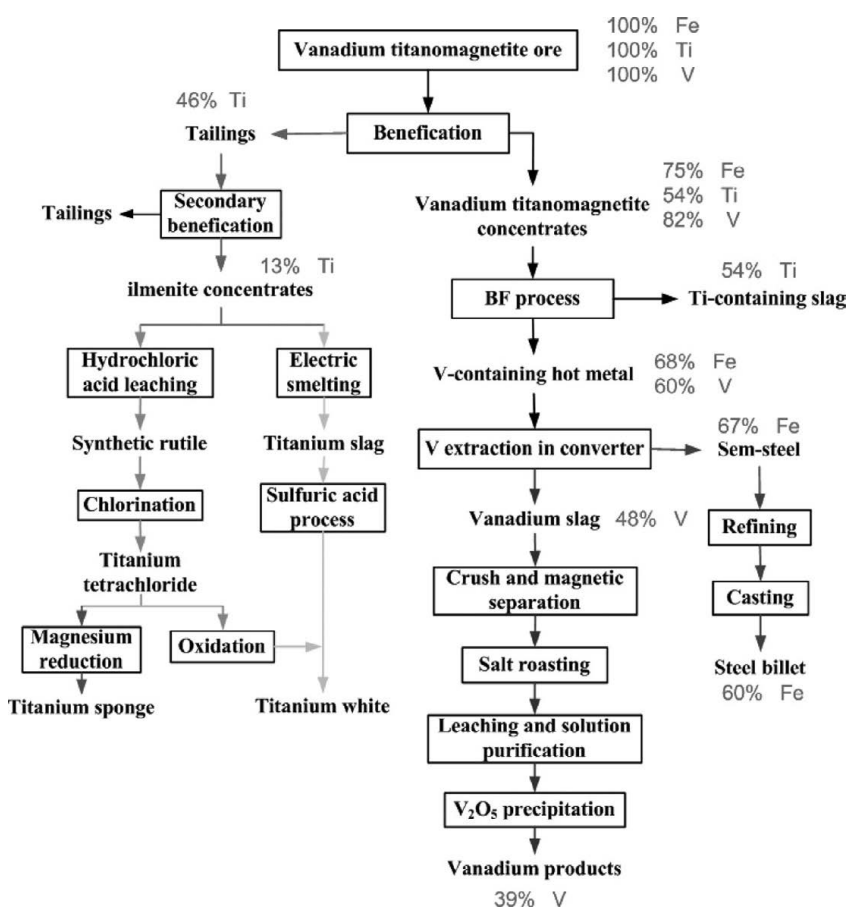

Fig. 1. Flow sheet of vanadium tianomagnetite processing and the element distribution. 
Table 1. Chemical composition of the magnetite and ilmenite (wt.\%).

\begin{tabular}{ccccccccccc}
\hline Ore & $\mathrm{TFe}$ & $\mathrm{FeO}$ & $\mathrm{TiO}_{2}$ & $\mathrm{~V}_{2} \mathrm{O}_{5}$ & $\mathrm{Cr}_{2} \mathrm{O}_{3}$ & $\mathrm{SiO}_{2}$ & $\mathrm{Al}_{2} \mathrm{O}_{3}$ & $\mathrm{CaO}$ & $\mathrm{MgO}$ & $\mathrm{MnO}$ \\
\hline Magnetite & $53-55$ & $20-23$ & $12-13$ & 0.60 & 0.45 & $2-3$ & $3-5$ & $\sim 1$ & $1-3$ & $<1$ \\
Ilmenite & $32-34$ & $34-36$ & $45-49$ & 0.10 & 0.30 & $3-4$ & $\sim 1$ & $\sim 1$ & $4-5$ & $<1$ \\
\hline
\end{tabular}

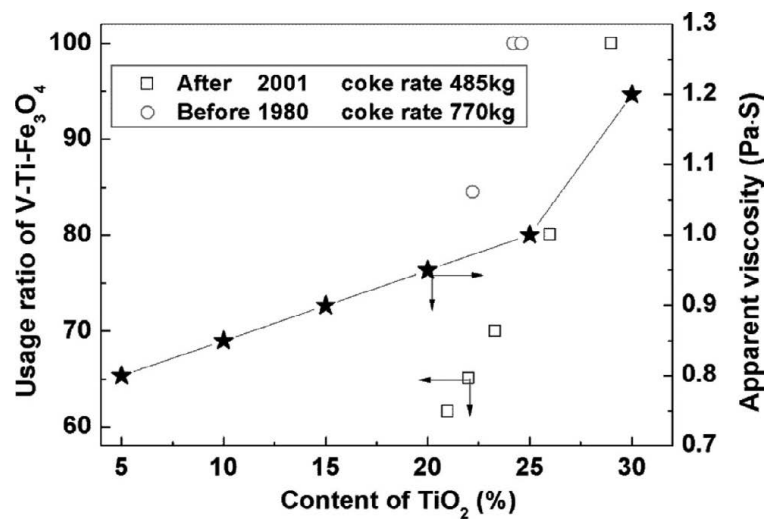

Fig. 2. Dependency of $\mathrm{TiO}_{2}$ content on the usage ratio of $\mathrm{V}-\mathrm{Ti}-$ $\mathrm{Fe}_{3} \mathrm{O}_{4}$ and the apparent viscosity.

$25 \%$ despite of the usage ratio of the vanadium titanomagnetite. The reason is that the $\mathrm{Ti}(\mathrm{C}, \mathrm{N})$ is formed easily in the hearth of the blast furnace if the content $\mathrm{TiO}_{2}$ beyond $25 \%$, resulting in the dramatic increase of the viscosity of the blast furnace slag and the difficulty of the separation between the slag and the hot metal. However, the utilization of the blast furnace slag containing high $\mathrm{TiO}_{2}$ is another big difficulty. The ability of milling of the slag is poor because of $\mathrm{CaTiO}_{3}$ with high hardness. The processing cost will increase if this slag is used as the materials for cement production. In the view of recovery of titanium, $20-25 \% \mathrm{TiO}_{2}$ is neither high for directly utilization nor low to drop off. A new process is necessary to be developed and the recovery rates of all metal elements require improvement. ${ }^{4-6)}$ Recently, the microwave was widely introduced to as a heat resource for the reduction of iron ore or the other minerals. For example, Ishizaki et al. studied the reduction behavior of magnetite and carbonaceous material by microwave irradiation, ${ }^{7)}$ Nishoka et al. also reported the reduction behavior of the iron ore by the plastic with the microwave heating. ${ }^{8)}$ Guo also studied the heating property of the ilmenite which is also a minor phase contained in the vanadium titanomagnetite. ${ }^{7,8)}$ Therefore, Carbothermic reduction assisted with microwave radiation was proposed to process the vanadium titanomagnetite ore in this study because microwave as the heating method will decrease the using amount of coal and the atmosphere is the microwave oven is not so reductive as that in blast furnace, the problem caused by $\operatorname{Ti}(\mathrm{C}, \mathrm{N})$ should be avoid. In addition, the $\mathrm{TiO}_{2}$ content in the slag should increase if the usage ratio of vanadium titanomagnetite increases and the flux used during the separation between the metal and slag decreases. Therefore, the new process, Carbothermic reduction assisted with microwave radiation followed by the smelting with EAF has the perspective potential to recovery the Ti from the vanadium titanomagnetite resource, is the objective of this study. As a simulation study of the proposal process, The reduction behavior of the vanadium titanomagnetite ore in the microwave process and the distribution of the elements during the smelting process were studied.
Table 2. Chemical composition of the vanadium titanomagnetite (wt.\%).

\begin{tabular}{ccccccccccc}
\hline Ore & $\mathrm{TFe}$ & $\mathrm{FeO}$ & $\mathrm{TiO}_{2}$ & $\mathrm{~V}_{2} \mathrm{O}_{5}$ & $\mathrm{Cr}_{2} \mathrm{O}_{3}$ & $\mathrm{SiO}_{2}$ & $\mathrm{Al}_{2} \mathrm{O}_{3}$ & $\mathrm{CaO}$ & $\mathrm{MgO}$ & $\mathrm{MnO}$ \\
\hline $\begin{array}{l}\mathrm{V}-\mathrm{Ti}- \\
\mathrm{Fe}_{3} \mathrm{O}_{4}\end{array}$ & 55.75 & 23.61 & 12.67 & 0.60 & 0.45 & 2.17 & 3.16 & 1.25 & 1.37 & 0.20 \\
\hline
\end{tabular}

Table 3. Chemical analysis of coke (wt.\%).

\begin{tabular}{|c|c|c|c|c|c|c|c|c|c|}
\hline \multirow{3}{*}{ Coke } & \multirow{2}{*}{ S } & \multirow{2}{*}{$\mathrm{P}$} & \multirow{2}{*}{$\begin{array}{l}\text { Fixed } \\
\text { carbon }\end{array}$} & \multirow{2}{*}{ Volatile } & \multirow{2}{*}{ Ash } & \multicolumn{4}{|c|}{ Ash } \\
\hline & & & & & & $\mathrm{Fe}_{2} \mathrm{O}_{3} \mathrm{CaO}$ & $\mathrm{Al}_{2} \mathrm{O}_{3}$ & $\mathrm{MgO}$ & $\mathrm{SiO}_{2}$ \\
\hline & 0.65 & 0.12 & 83.66 & 6.32 & 9.20 & $8.91 \quad 6.01$ & 22.26 & 2.16 & 47.79 \\
\hline
\end{tabular}

\section{Experimental}

The vanadium titanomagnetite ore was got from Panzhihua, Sichuan, China. The chemical composition is shown in Table 2. The coal used was got from one steel plant, and the industrial analysis of the coal is shown in Table 3. The analysis grade of $\mathrm{CaO}$ was used as the flux and the purification degree of the $\mathrm{CaO}$ is above $98 \%$. The molar ratio of $\mathrm{C}_{\text {fixed }} /$ $\mathrm{O}_{\text {(bonded with } \mathrm{Fe} \text { ) }}$ in the study was fixed at 1.2. The materials were weighted and mixed homogeneously. The microwave oven used in this study is from Taiyuan University of technology, Shanxi, China. The schematic figure of the microwave oven and the crucible used are shown in Fig. 3. The frequency of the microwave is $2.45 \mathrm{GHz}$. The maximum power of the microwave is $15 \mathrm{kw}$ and the power used in this study is kept at $10 \mathrm{kw}$. The temperature was measured by thermocouple, which was immerged into the samples contained in the crucible.

The phase composition of the original sample and the sample reduced were check by X-ray diffraction method which is carried on D/MAX $3 \mathrm{C}(\mathrm{Co} \mathrm{K} \alpha)$.

The smelting process of the reduced samples in the microwave oven was also carried out in an induced furnace, which was designed by the Shanghai experimental electric furnace company, with power of $50 \mathrm{kVA}$ medium frequency (1.0 kHz single phase). The temperature during the process was about $1550^{\circ} \mathrm{C}$. The metal separated from the slag during the smelting process. The samples of the metal and the slag were analyzed after separation.

The experimental schedule is shown in Table 4. There are six runs of the experiment. The first four runs in which $1 \mathrm{~kg}$ pellets made with the mixture of concentrate and coke were used to check the effect of heating pattern, $\mathrm{CaO}$ addition and the thermal insulation on the reduction. According to the ternary phase diagram of $\mathrm{TiO}_{2}-\mathrm{SiO}_{2}-\mathrm{CaO}, 4.5 \% \mathrm{CaO}$ was added into the concentrate to easily form the liquid phase in the slag, which is good for the separation between the metal and slag. The last two runs in which $1.6 \mathrm{~kg}$ powder of mixture was used to check the influence the flux addition and the total mass on the reduction.

\section{Results and Discussion}

\subsection{Heating Feature of the Vanadium Titanomagnetite in the Microwave Field}

The major advantages of using microwaves for industrial processing are rapid heat transfer, volumetric and selective heating. The heating curves of the samples are shown in Fig. 

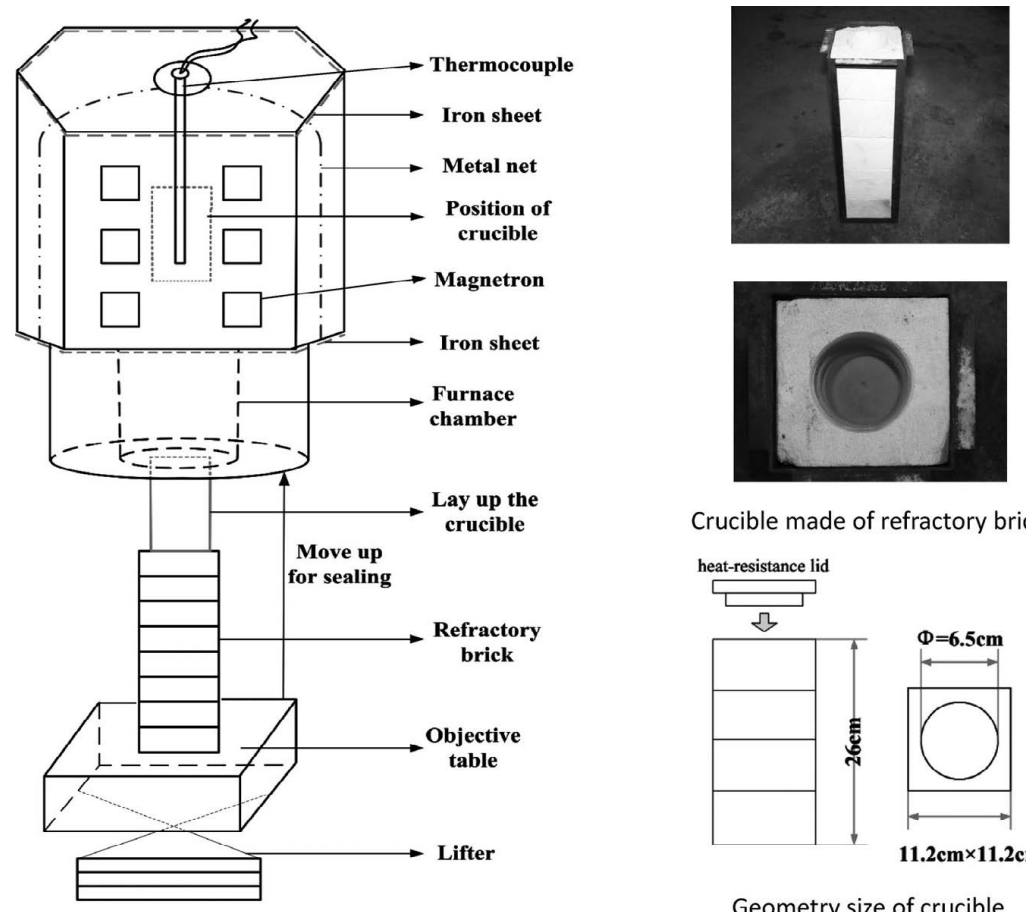

Crucible made of refractory brick

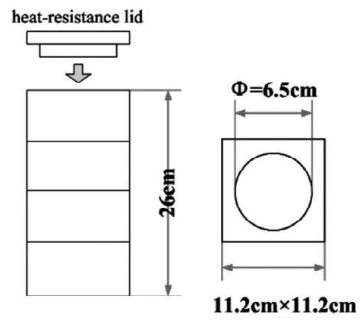

Geometry size of crucible

Fig. 3. Schematic figure of the microwave oven $(2.45 \mathrm{G}, 15 \mathrm{kw})$ and crucible.

Table 4. Experimental scheme of the reduction of vanadium titanomagnetite with microwave.

\begin{tabular}{|c|c|c|c|c|}
\hline No. & $\begin{array}{c}\mathrm{CaO} \\
\text { addition }\end{array}$ & Sample & Mass & Notes \\
\hline 1 & No & Pellets & $1 \mathrm{~kg}$ & Heating to $1250^{\circ} \mathrm{C}$ and keep for $0.5 \mathrm{~h}$ \\
\hline 2 & No & Pellets & $1 \mathrm{~kg}$ & heating for $2 \mathrm{~h}, 1287^{\circ} \mathrm{C}$ reached \\
\hline 3 & No & Pellets & $1 \mathrm{~kg}$ & With lid, heating for $2 \mathrm{~h}, 1280^{\circ} \mathrm{C}$ reached \\
\hline 4 & Yes & Pellets & $1 \mathrm{~kg}$ & With lid, heating to $1250^{\circ} \mathrm{C}$ and keep for $0.5 \mathrm{~h}$ \\
\hline 5 & No & Powder & $1.6 \mathrm{~kg}$ & With lid, heating to $1350^{\circ} \mathrm{C}$ and keep for $0.5 \mathrm{~h}$ \\
\hline 6 & Yes & Powder & $1.6 \mathrm{~kg}$ & With lid, heating to $1350^{\circ} \mathrm{C}$ and keep for $0.5 \mathrm{~h}$ \\
\hline
\end{tabular}

4. It shows that the heating rates of all the samples in the first 10 minutes are very similar, all the samples can reach $600^{\circ} \mathrm{C}$ quickly at the same time, the heating rate was about $60^{\circ} \mathrm{C} \mathrm{m^{-1 }}$. The heating difference gradually appears after 10 minutes. The temperature difference between the powder sample and pellet sample becomes great after 25 minutes. The samples with less mass $(1 \mathrm{~kg})$ can still have a relative high heating rate and can reach $1250^{\circ} \mathrm{C}$ after another 50 minutes (total 75 minutes). However, for the samples with more mass $(1.6 \mathrm{~kg})$, the heating rate is very different with the four samples with less mass. The heating process can be divided into three stages according to the change of heating rate, which is shown in Fig. 5. It shows that the heating rate reach the maximum at 10 minutes. There are general two heating rate peaks in all the heating curves. It should be caused by the phase transformation during the reduction; the detail explanation was given in the following part. The first stage ends after 25 minutes, the second one begins from the 25 minutes and end at the 75 minutes for sample No. 6 and 100 minutes for sample No. 5. The average heating rate during the second stage are about $2.3^{\circ} \mathrm{C} \mathrm{min}^{-1}$ and $2.9^{\circ} \mathrm{C} \mathrm{min}^{-1}$ for the samples No. 5 and No. 6 respectively. The heating rate for the samples No. 5 and No. 6 in the

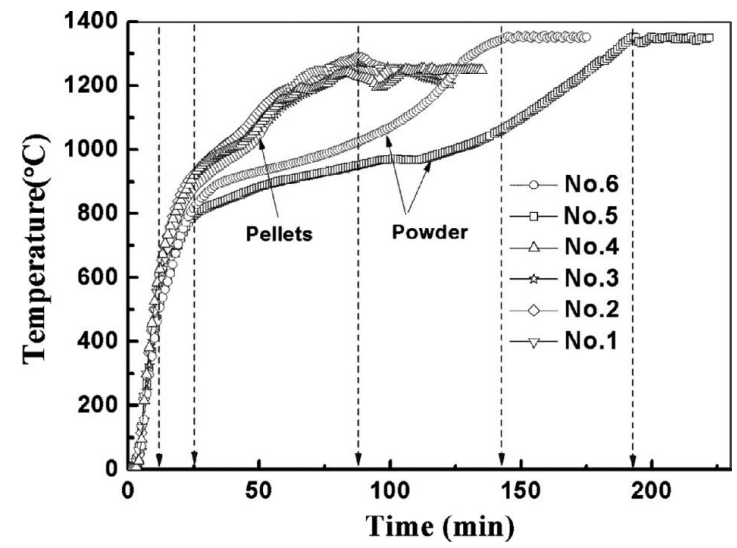

Fig. 4. Relationship between the time and temperature for various samples.

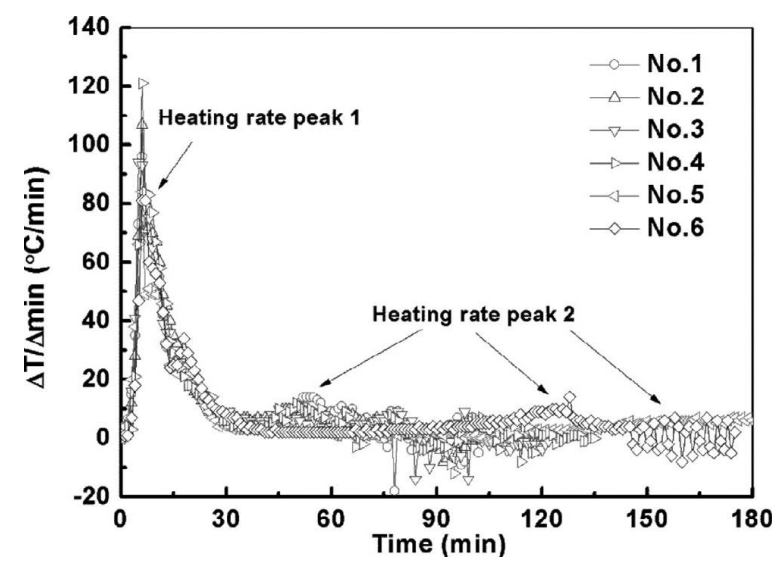

Fig. 5. Heating rate for the various samples.

third stage return to high value, which is about $4^{\circ} \mathrm{C} \min ^{-1}$ and $5^{\circ} \mathrm{C} \mathrm{min}^{-1}$ individually.

Combing the reduction behavior of the vanadium titano- 
magnetite with the heating curves, it indicates that the gas reduction of the magnetite by $\mathrm{CO}\left(730-960^{\circ} \mathrm{C}\right)$ decreases the heating rate of samples because 1) as a good microwave absorbent, magnetic decrease with the reduction, 2) the reduction of the magnetite is the endothermic reaction. After most of the magnetite is reduced to the wusitite, the absorption of microwave by the un-react coke and ilmenite can heat the sample to the higher temperature. Once the samples reach to about $1200^{\circ} \mathrm{C}$, the reduction of ilmenite, ${ }^{9,10)}$ resulting the decrease of ilmenite can slow the heating rate of the sample, causing the appearance of second heating rate peak.

The effect of heat-resistance lid which was put on the top of the crucible on the microwave heating can be got by comparing samples No. 1-4. It indicates that there is less influence of the top heat preserve method on the heating rate. The influence of $\mathrm{CaO}$ addition on the heating rate can be got by comparing sample No. 1 with No. 4 , and No. 5 with No. 6. It indicates that the addition of $\mathrm{CaO}$ has less effect on the heating behavior of the pellets.

Table 5. Chemical compostion of the sample reduced (\%).

\begin{tabular}{cccccc}
\hline No. & TFe & MFe & $\mathrm{FeO}$ & $\mathrm{C}$ & $\mathrm{M}_{\mathrm{R}}$ \\
\hline 1 & 56.08 & 29.29 & 17.67 & 1.72 & 52.2 \\
2 & 58.31 & 33.93 & 21.01 & 0.89 & 58.2 \\
3 & 58.70 & 34.68 & 20.58 & 0.88 & 59.1 \\
4 & 52.07 & 31.51 & 15.86 & 0.61 & 60.5 \\
5 & 63.81 & 41.33 & 11.34 & 0.39 & 64.8 \\
6 & 52.19 & 35.15 & 12.76 & 0.14 & 67.3 \\
\hline & & & & &
\end{tabular}

\subsection{Reduction Behavior of the Vanadium Titanomag- netite in the Microwave Field}

The reduction behavior in present study refers to the metallization ratio of the sample reduced, which is defined as:

$$
\mathrm{Mr}=\frac{\mathrm{MFe}}{\mathrm{TFe}} \times 100 \%
$$

where, MFe and TFe are the mass fraction of the metallic iron and the total iron in the samples reduced respectively.

The chemical composition of the sample reduced is shown in Table 5. It indicates that the metallization ratio of the sample increases with increasing the maximum temperature reached. The addition of $\mathrm{CaO}$ is good for the enhancement of the metallization ratio of the sample; the possible reason for this is that the addition of $\mathrm{CaO}$ can increase the reducibility of iron oxide. ${ }^{11)}$ The phase composition of the samples is shown in Fig. 6. It indicates that the main phase

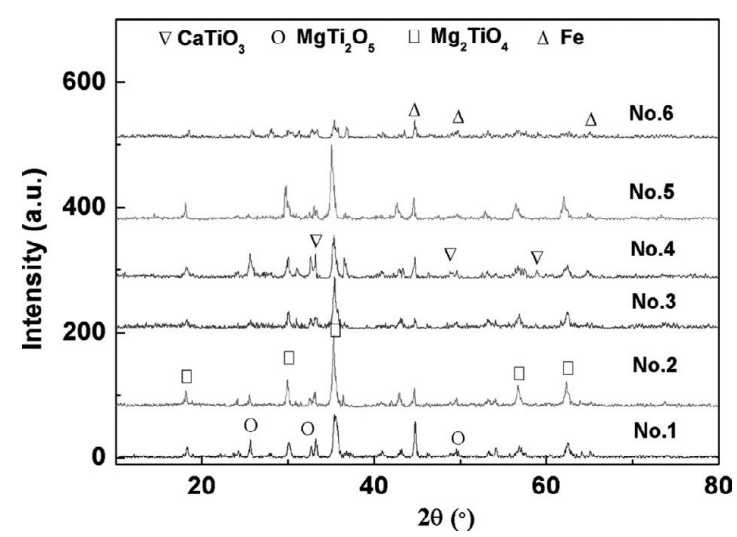

Fig. 6. XRD pattern of the samples reduced in the microwave field.

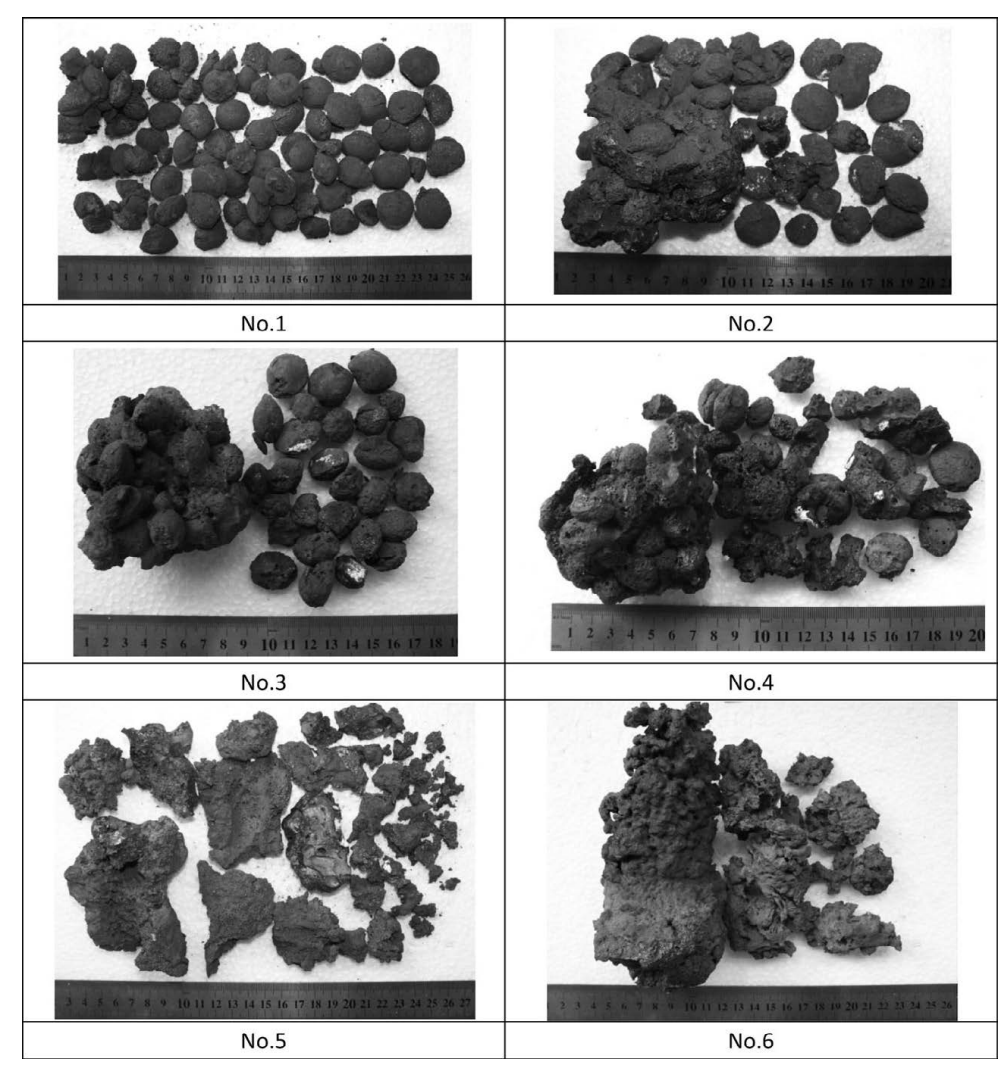

Fig. 7. Appearance of the samples reduced. 
in the samples is $\mathrm{Fe}, \mathrm{MgTi}_{2} \mathrm{O}_{5}, \mathrm{Mg}_{2} \mathrm{TiO}_{4}$ and $\mathrm{CaTiO}_{3}$. The diffraction peaks of $\mathrm{CaTiO}_{3}$ in the samples No. 4 and No. 6 are relative higher than others because of the addition of $\mathrm{CaO}$.

The appearance of the samples reduced is shown in Fig. 7. Generally, the samples No. 5 and No. 6 agglomerated greatly after reduction, in which more liquid phase formed during the reduction because of the high temperature. Sample No. 6 with $\mathrm{CaO}$ addition has more big bulk than that of No. 5. For the samples No. 1-No. 4, No. 2 with a high temperature and No. 6 with $\mathrm{CaO}$ addition generated more liquid phase.

\subsection{Recovery Ratio of the Elements After Smelting Process}

The sample after smelting was shown in Fig. 8. The metal went down to the bottom of the crucible and the high titanium slag was on the top. The recovery ratio of the elements such as $\mathrm{Fe}, \mathrm{V}$ and $\mathrm{Si}$ is generally defined as:

$$
\mathrm{R}_{\mathrm{e}}=\frac{\mathrm{M}_{\mathrm{e}}}{\mathrm{O}_{\mathrm{e}}} \times 100 \%
$$

where, $\mathrm{Re}, \mathrm{Me}$, Oe represent the recovery ratio, mass of the element in metal and the mass of the element in the ore respectively. The results of the recovery ratio calculated are shown in Fig. 9. It indicate that the recovery ratio of the Fe, $\mathrm{V}$ and $\mathrm{Si}$ increase with increasing the maximum temperature of the samples reached which is shown in Table 4. The addition of the $\mathrm{CaO}$ can leads to suppression of reduction of $\mathrm{SiO}_{2}$, because the addition of $\mathrm{CaO}$ can steady $\mathrm{SiO}_{2}$, resulting more difficult to reduce the Si with carbon.

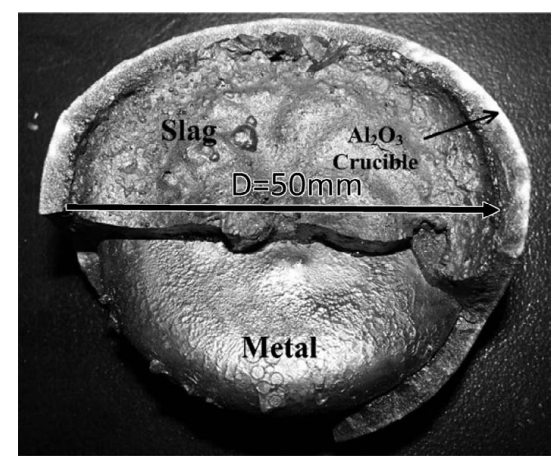

Fig. 8. Appearance of the metal and slag after separation.

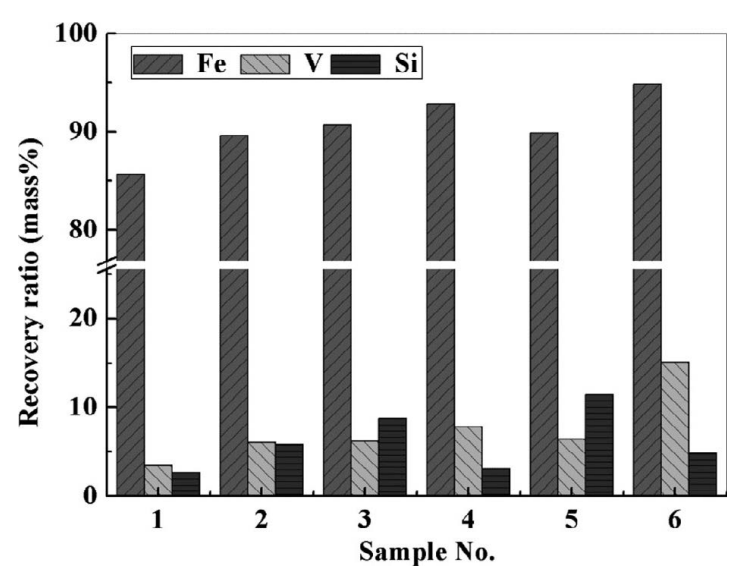

Fig. 9. Recovery ratio of the elements after smelting process.
The recovery ratio of $\mathrm{Fe}$ and $\mathrm{V}$ is only about $90 \%$ and $6 \%$ respectively in the new process which is reduction with carbon assisted with microwave followed by smelting process. It means that after the smelting process, about more than $90 \% \mathrm{~V}$ and about $10 \% \mathrm{Fe}$ are still remained in the slag. Therefore, another further reduction process which can produce high vanadium ferrous alloy is available. For the traditional BF-BOF process, the enrichment of the $\mathrm{V}$ by calcinations with sodium slat or calcium salt and followed by leaching process is necessary to produce $\mathrm{V}_{2} \mathrm{O}_{5}$ which is the raw material for high vanadium ferrous alloy, which always causes the environment pollution and requires the process investment. In the non-BF process presented in this study, the high vanadium ferrous alloy can be directly produced in the smelting furnace after dapping of the semisteel, which is a short process for high efficiency.

\section{Conclusions}

The reduction of vanadium titanomagnetite assisted with microwave radiation was carried out in present study. The conclusion can be summarized as follows:

(1) The heating rate of the vanadium titanomagnetite in the microwave field can be divided into three stages: the very fast heating period in initial 25 minutes in which no apparent reduction happens, the slow heating period in which the solid reduction of the magnetite decreases the heating rate, another fast heating period in which the reduction of ilmenite happens.

(2) About $60 \%$ of iron from $1 \mathrm{~kg}$ of the ore and carbonaceous materials was obtained by an energy supply of 10 $\mathrm{kW}$ by microwave irradiation in $120 \mathrm{~min}$. The minimum power supply for this reduction performance need further study.

(3) The recovery ratio of the Fe, $\mathrm{V}$ and $\mathrm{Si}$ increase with increasing the reduction temperature. The addition of the $\mathrm{CaO}$ can increase the recovery ratio of $\mathrm{Fe}$ and $\mathrm{V}$, but decrease the recovery ratio of $\mathrm{Si}$.

\section{Acknowledgments}

The authors are especially grateful to Fundamental Research Funds for the Central Universities (Grant No. CDJZR11130002).

\section{REFERENCES}

1) D.-s. Chen, B. Song, L.-n. Wang, T. Qi, Y. Wang and W.-j. Wang: Miner. Eng., 24 (2011), 864.

2) R. Liao and B. Yang: China Nonferrous Metals, 27 (2010), 27.

3) J. Ma, X. Sun and R. Diao: Theory and Practice of Blast Furnace Operation with V-Ti-Magnetite, Metallurgical Industrial Publisher China, Beijing, (2000).

4) M. Xu, M. W. Guo, J. L. Zhang, T. J. Wan and L. T. Kong: J. Iron Steel Res. Int., 13 (2006), 6.

5) A. T. Tang, F. S. Pan, L. Y. Wang, Y. Lu, K. Li and J. Zhang: Proc. 2nd Int. Conf. on Advanced Materials Processing, Vol. 437-4, Trans Tech Publications, Switzerland, (2003), 149.

6) W. B. Li, Z. F. Yuan, C. Xu, Y. F. Pan and X. Q. Wang: J. Iron Steel Res. Int., 12 (2005), 1.

7) P. Jinhui, $Y$. Jingjing, $H$. Ming and H. Mengyang: Proc. 8th Int. Symp. on Antennas, Propagation \& EM Theory (ISAPE - 2008), IEEE, Beijing, China, (2008), 1383.

8) S. H. Guo, W. Li, J. H. Peng, H. Niu, M. Y. Huang, L. B. Zhang, S. M. Zhang and M. Huang: Int. J. Miner. Process., 93 (2009), 289.

9) G. Q. Zhang and O. Ostrovski: Can. Metall. Q., 40 (2001), 489.

10) G. Q. Zhang and O. Ostrovski: Can. Metall. Q., 40 (2001), 317.

11) B. B. L. Seth and H. U. Ross: Can. Metall. Q., 2 (1963), 15. 